\title{
Compensatory sweating after thoracoscopic sympathectomy: characteristics, prevalence and influence on patient satisfaction*,**
}

\author{
Hiperhidrose compensatória após simpatectomia toracoscópica: \\ caracteristicas, prevalência e influência na satisfação do paciente \\ Carlos Alberto Almeida de Araújo, Ítalo Medeiros Azevedo, \\ Maria Angela Fernandes Ferreira, Hylas Paiva da Costa Ferreira, \\ Jorge Lúcio Costa de Medeiros Dantas, Aldo Cunha Medeiros
}

\begin{abstract}
Objective: This prospective study aimed at investigating predictive factors for compensatory sweating after thoracoscopic sympathectomy. Methods: From 2000 to 2002, 80 patients ( 53 females and 27 males) underwent thoracoscopic sympathectomy to treat hyperhidrosis. Patient ages ranged from 12 to 56 years, and the mean postoperative follow-up period was $42.51 \pm 5.98$ months. Patient satisfaction with the results was evaluated through the use of a rating scale. The procedure was performed bilaterally: at the T2 level for facial hyperhidrosis; at the T3-T4 level for axillary hyperhidrosis; and at the T3 level for palmar hyperhidrosis. Results: Post-operatively, 68 patients $(85.0 \%)$ presented compensatory sweating, which was classified as mild in $23(33.8 \%)$, moderate in $23(33.8 \%)$ and severe in $22(32.4 \%)$. Considering the final surgical results, 70 patients (87.5\%) were satisfied with the outcome of the operation, whereas 10 patients (12.5\%) were dissatisfied. The level of patient satisfaction varied according to gender, age, body mass index (BMI) and extent of denervation. The compensatory sweating was more severe on the abdomen and back than on the legs. Conclusions: Although compensatory sweating, which is a common adverse effect of sympathectomy, occurred in the majority of cases, the level of patient satisfaction was high. The best candidates for thoracoscopic sympathectomy are young adult women with a BMl $\leq 24.9 \mathrm{~kg} / \mathrm{m}^{2}$.
\end{abstract}

Keywords: Sympathectomy; Hyperhidrosis; Thoracoscopy; Postoperative complications;

Thoracic surgery, video-assisted.

\section{Resumo}

Objetivo: Este estudo prospectivo visou investigar fatores preditivos para a hiperidrose compensatória após a simpatectomia toracoscópica. Métodos: De 2000 a 2002, 80 pacientes ( 53 mulheres e 27 homens), com idade entre 12 e 56 anos, foram submetidos à simpatectomia toracoscópica para o tratamento de hiperidrose e acompanhados em média por 42,51 \pm 5,98 meses. A satisfação destes pacientes quanto aos resultados do procedimento foi aferida por meio de uma escala de avaliação. 0 procedimento foi executado bilateralmente: no nível de T2 para a hiperidrose facial; de T3 e T4 para a hiperidrose axilar; e de T3 para a hiperidrose palmar. Resultados: No período pós-operatório, 68 pacientes $(85,0 \%)$ apresentaram hiperidrose compensatória, que foi classificada como leve em 23 (33,85\%), moderada em $23(33,8 \%)$ e grave em 22 (32,4\%). Quanto aos resultados da cirurgia, na avaliação dos pacientes, 70 deles $(87,5 \%)$ se consideraram satisfeitos, enquanto 10 pacientes $(12,5 \%)$ disseram estar insatisfeitos. 0 grau de satisfação do paciente variou de acordo com o sexo, a idade, o índice de massa corpórea (IMC) e a extensão da operação. A hiperidrose compensatória foi mais intensa no abdome e dorso do que nas pernas. Conclusões: Embora a hiperidrose compensatória seja um efeito adverso frequente após a simpatectomia, o grau de satisfação dos pacientes foi elevado. Os melhores candidatos para simpatectomia toracoscópica são mulheres adultas jovens com $\mathrm{IMC} \leq 24,9 \mathrm{~kg} / \mathrm{m}^{2}$.

Descritores: Simpatectomia; Hiperidrose; Toracoscopia; Complicações pós-operatórias; Cirurgia torácica vídeo-assistida.

\footnotetext{
* Study carried out at the Universidade Federal do Rio Grande do Norte - UFRN, Federal University of Rio Grande do Norte - Natal, Brazil.

Correspondence to: Carlos Alberto Almeida de Araújo. Rua Gustavo Cordeiro de Farias, S/N, Petrópolis, CEP 59010-180, Natal, RN, Brasil. Tel 5584 3202-0453. E-mail: cabeto@digi.com.br

Financial support: None.

Submitted: 23 April 2007. Accepted, after review: 13 August 2008.

**A versão completa em português deste artigo está disponivel em www.jornaldepneumologia.com.br
} 


\section{Introduction}

Hyperhidrosis is an idiopathic condition characterized by excessive sweating. Symptoms generally begin in childhood or early adolescence and rarely improve with age. The excessive localized sweating generally occurs either spontaneously or in response to stressful or emotionally charged situations. Severe hyperhidrosis typically affects the palms and feet, with or without axillary involvement. In fact, palmar hyperhidrosis is the most common and most debilitating condition. In severely affected patients, hyperhidrosis can be socially, psychologically and professionally stigmatizing. ${ }^{(1,2)}$

Thoracoscopic sympathectomy is a safe and effective method of treating hyperhidrosis, resulting in improved patient quality of life. ${ }^{(3-7)}$ Despite the effectiveness of the method, there can be post-operative complications, the most troublesome of which is compensatory sweating. ${ }^{(4,5,7,7)}$ In fact, compensatory sweating is the factor that most influences the post-operative quality of life of the patients, and it is said to be a marker of the quality of the sympathectomy. ${ }^{(3,5)}$ Pre-operative and post-operative patient perceptions regarding the sweating disorder play a major role in post-operative complaints and, consequently, in determining the level of patient satisfaction..$^{(7-9)}$

To achieve a high level of patient satisfaction, it is useful to identify some predictive factors for compensatory sweating. ${ }^{(10)}$ ldentifying the profile of the ideal candidate for thoracoscopic sympathectomy is of utmost importance and facilitates the appropriate selection of patients. The aim of this study was to investigate predictive factors for compensatory sweating after thoracoscopic sympathectomy, as well as their influence on the frequency, location and severity of compensatory sweating.

\section{Methods}

Between February of 2000 and April of 2002, 80 patients underwent video-assisted thoracoscopic sympathectomy for hyperhidrosis in the Thoracic Surgery Department of the Onofre Lopes University Hospital, located in the city of Natal, Brazil. After a mean follow-up period of $42.51 \pm 5.98$ months, data were available for all 80 patients. The study was approved by the institutional ethics committee and was performed in accordance with the Helsinki Declaration. Written informed consent was obtained from each patient.

Demographic and pre-operative characteristics of the patients are shown in Table 1. Of the 80 patients included in the sample, 27 (33.7\%) were male and $53(66.3 \%)$ were female. The mean age at the time of surgery was $26.83 \pm$ 10.17 years (range, 12-56 years). We collected data related to the duration of the problem, the area(s) affected, precipitating factors, body mass index (BMI) and surgical details, as well as post-operative complications and outcomes. Patient satisfaction with the results was evaluated through the use of a 10-point rating scale based on patient perception (Appendix 1). ${ }^{(11)}$ The degree of sweating in the various areas affected (abdomen, back and legs) was scored pre-operatively and post-operatively. Patients completed the scale without any intervention or advice from the interviewer. Post-operative compensatory sweating was graded as follows: $1-4=$ mild; 5-7 = moderate; and 8-10 = severe. A score of 10 was indicative of the most severely affected area, and the other scores were given accordingly. Finally, patients were asked whether they

Table 1 - Characteristics of the patient sample $(n=80)$.

\begin{tabular}{|c|c|c|}
\hline Characteristic & $\mathrm{n}$ & $\%$ \\
\hline \multicolumn{3}{|l|}{ Gender } \\
\hline Male & 27 & 33.7 \\
\hline Female & 53 & 66.3 \\
\hline \multicolumn{3}{|l|}{ Average patient age } \\
\hline Adolescent & 17 & 21.3 \\
\hline Adult & 56 & 70.0 \\
\hline Middle-aged & 7 & 8.8 \\
\hline \multicolumn{3}{|c|}{ Duration of the problem } \\
\hline$<1$ year & 3 & 3.75 \\
\hline $1-5$ years & 5 & 6.25 \\
\hline $5-10$ & 10 & 12.5 \\
\hline$>10$ years & 62 & 77.5 \\
\hline \multicolumn{3}{|l|}{ Hyperhidrosis location } \\
\hline Axillary & 8 & 10.0 \\
\hline Multi-area & 72 & 90.0 \\
\hline \multicolumn{3}{|l|}{$\mathrm{BMl}$} \\
\hline$<19.9 \mathrm{~kg} / \mathrm{m}^{2}$ & 16 & 20.0 \\
\hline $19.9-24.8 \mathrm{~kg} / \mathrm{m}^{2}$ & 49 & 61.3 \\
\hline $24.9-29.9 \mathrm{~kg} / \mathrm{m}^{2}$ & 10 & 12.5 \\
\hline$>29.9 \mathrm{~kg} / \mathrm{m}^{2}$ & 5 & 6.3 \\
\hline
\end{tabular}

BMl: body mass index. 
were satisfied with the outcome of the procedure. Patients were evaluated and completed the scale on post-operative day 13 , in the sixth post-operative month and at one year after the procedure.

\section{Surgical technique}

All patients underwent surgery in the supine position with both arms elevated at 45 degrees. The patients received general anesthesia and were submitted to endotracheal intubation using a single-lumen tube. Subsequently, two ports were placed. The first incision $(20 \mathrm{~mm})$ was made anteriorly. The endotracheal tube was briefly disconnected by the anesthesiologist in order to deflate the lung during entry into the pleural cavity, thereby avoiding damage to the lung parenchyma. A 10-mm blunt-tip trocar was introduced for the use of a 30-degree endoscope (Olympus Winter \& lbe, Hamburg, Germany), and pneumothorax was induced via $\mathrm{CO}_{2}$ insufflation up to $10 \mathrm{mmHg}$. A $1-\mathrm{cm}$ incision was made in the third intercostal space below the axilla, and an additional 5-mm trocar was placed for the introduction of a monopolar hook electrode for cautery. The sympathetic chain was identified at the level of the second, third, and fourth rib heads. The procedure was performed bilaterally: at the T2 level for facial hyperhidrosis; at the T3-T4 level for axillary hyperhidrosis; and at the T3 level for palmar hyperhidrosis. When patients were treated for more than one area, multiple segments were incised, although the rest of the chain was left intact. The pneumothorax was aspirated using a chest tube, which was removed after total aspiration. A chest X-ray was performed after surgery to verify complete lung expansion. Patients were discharged on the first post-operative day.

\section{Statistical analysis}

Data were stored in a database and exported to the Statistical Package for the Social Science, version 14.0 (SPSS Inc., Chicago, IL, USA) for analysis. Pearson's chi-square test, Fisher's exact test, means and standard deviations were used as appropriate.

\section{Results}

There were no deaths or major peri-operative complications in our patient sample. The patients required an overnight hospital stay. The mean surgical time was $20 \mathrm{~min}$ (range, 10-30 min). Sixty-eight patients $(85.0 \%)$ presented postoperative compensatory sweating, which was classified as mild/moderate or severe (Table 2).

We found that 70 patients $(87.5 \%)$ were satisfied with the outcome of the operation, whereas 10 patients $(12.5 \%)$ were dissatisfied. Women presented the highest level of satisfaction ( $p=$ 0.026), accounting for $71.4 \%$ of the satisfied

Table 2 - Severity of compensatory sweating on the abdomen and back according to gender, age, body mass index and number of ganglia denervated.

\begin{tabular}{|c|c|c|c|c|c|c|c|c|c|c|}
\hline \multirow[t]{3}{*}{ Variable } & \multicolumn{5}{|c|}{ Abdomen } & \multicolumn{5}{|c|}{ Back } \\
\hline & \multicolumn{2}{|c|}{ Mild/Mod } & \multicolumn{2}{|c|}{ Severe } & \multirow[t]{2}{*}{$p$} & \multicolumn{2}{|c|}{ Mild/Mod } & \multicolumn{2}{|c|}{ Severe } & \multirow[t]{2}{*}{$\mathrm{p}$} \\
\hline & $\mathrm{n}$ & $\%$ & $n$ & $\%$ & & $\mathrm{n}$ & $\%$ & $n$ & $\%$ & \\
\hline \multicolumn{11}{|l|}{ Gender } \\
\hline Male & 11 & 45.8 & 13 & 54.2 & $0.001^{* *}$ & 13 & 54.2 & 11 & 45.8 & $0.012^{* * *}$ \\
\hline Female & 32 & 84.2 & 6 & 15.8 & & 34 & 82.9 & 7 & 17.1 & \\
\hline \multicolumn{11}{|l|}{ Age bracket } \\
\hline Adolescent & 11 & 91.7 & 1 & 8.3 & $0.016^{*}$ & 11 & 84.6 & 2 & 15.4 & $0.133^{*}$ \\
\hline Adult & 30 & 69.8 & 13 & 30.2 & & 33 & 73.3 & 12 & 26.7 & \\
\hline Middle-aged & 2 & 28.6 & 5 & 71.4 & & 3 & 42.9 & 4 & 57.1 & \\
\hline \multicolumn{11}{|l|}{ BMl } \\
\hline$\leq 24.9 \mathrm{~kg} / \mathrm{m}^{2}$ & 36 & 73.5 & 13 & 26.5 & $0.172^{* * *}$ & 41 & 78.8 & 11 & 21.2 & $0.504^{* * *}$ \\
\hline$>24.9 \mathrm{~kg} / \mathrm{m}^{2}$ & 7 & 53.8 & 6 & 46.2 & & 6 & 46.2 & 7 & 53.8 & \\
\hline \multicolumn{11}{|c|}{ Resected ganglia (n) } \\
\hline 1 & 10 & 90.9 & 1 & 9.1 & $0.217^{*}$ & 11 & 84.6 & 2 & 15.4 & $0.241^{*}$ \\
\hline 2 & 20 & 66.7 & 10 & 33.3 & & 24 & 75.0 & 8 & 25.0 & \\
\hline 3 & 13 & 61.9 & 8 & 38.1 & & 12 & 60.0 & 8 & 40.0 & \\
\hline
\end{tabular}

BMI: body mass index; and Mod: moderate. *Fisher's exact test. *Pearson's chi-square test. 
Table 3 - The degree of patient satisfaction according to gender, age range, body mass index and denervation site.

\begin{tabular}{|c|c|c|c|c|c|}
\hline \multirow[t]{2}{*}{ Variable } & \multicolumn{2}{|c|}{ Satisfied } & \multicolumn{2}{|c|}{ Dissatisfied } & \multirow[t]{2}{*}{$\mathrm{p}^{*}$} \\
\hline & $\mathrm{N}$ & $\%$ & $\mathrm{~N}$ & $\%$ & \\
\hline \multicolumn{6}{|l|}{ Gender } \\
\hline Male & 20 & 74.1 & 7 & 25.9 & 0.026 \\
\hline Female & 50 & 94.3 & 3 & 5.7 & \\
\hline \multicolumn{6}{|l|}{ Age bracket } \\
\hline Adolescent & 16 & 94.1 & 1 & 5.9 & 0.001 \\
\hline Adult & 51 & 91.1 & 5 & 8.9 & \\
\hline Middle-aged & 3 & 42.9 & 4 & 57.1 & \\
\hline \multicolumn{6}{|l|}{$\mathrm{BMl}$} \\
\hline$\leq 24.9 \mathrm{~kg} / \mathrm{m}^{2}$ & 62 & 95.4 & 3 & 4.6 & $<0.001$ \\
\hline$>24.9 \mathrm{~kg} / \mathrm{m}^{2}$ & 8 & 53.3 & 7 & 46.7 & \\
\hline \multicolumn{6}{|c|}{ Resected ganglia (n) } \\
\hline 1 & 19 & 95.0 & 1 & 5.0 & 0.009 \\
\hline 2 & 35 & 94.6 & 2 & 5.4 & \\
\hline 3 & 16 & 69.6 & 7 & 30.4 & \\
\hline
\end{tabular}

BMl: body mass index. *Fisher's exact test.

patients, whereas $70.0 \%$ of the dissatisfied patients were men (Table 3). Patient satisfaction also varied according to age, BMl and extent of denervation. Of the 7 middle-aged patients, $4(57.1 \%)$ were dissatisfied $(p=0.01)$. Of the 65 patients with a BMl $\leq 24.9 \mathrm{~kg} / \mathrm{m}^{2}, 62(95.4 \%)$ were satisfied. In contrast, only 8 (53.3\%) of the 15 patients with a BMl $>24.9 \mathrm{~kg} / \mathrm{m}^{2}$ were satisfied $(p=0.001)$. With respect to the incision of the sympathetic chain, patients who underwent denervation of 1 or 2 ganglia were significantly more likely to have a favorable opinion of the outcome, which was held by $95.0 \%$ and $94.6 \%$, respectively, than were those undergoing denervation of 3 ganglia, only $69.6 \%$ of whom reported being satisfied $(p=0.009)$.

The severity of compensatory sweating depended on the area affected (abdomen, back or legs). Of the 80 patients evaluated, only $12(15.0 \%)$ presented no compensatory sweating, $4(5.0 \%)$ presented compensatory sweating at one site, and $64(80.0 \%)$ presented compensatory sweating at two or more sites. Severe compensatory sweating occurred on the abdomen and the back, respectively, in 19 (23.8\%) and 18 (22.5\%) of the patients (Figure 1). However, only 7 (3.8\%) presented compensatory sweating on the legs. The severity of compensatory sweating on the abdomen and back was analyzed according to gender, age, BMl and number of ganglia denervated (Table 2). Among the 11 adolescent patients who presented compensatory sweating, abdominal sweating was severe in only 1 (8.3\%), compared with $13(30.2 \%)$ of the adult patients and $5(71.4 \%)$ of the middle-aged patients $(p=$ 0.016). In addition, the proportion of patients reporting compensatory sweating on the abdomen was greater among males than among females (54.2\% vs. $15.8 \% ; p=0.001)$. Of the 7 patients with a $\mathrm{BMl}>24.9 \mathrm{~kg} / \mathrm{m}^{2}, 4(53.8 \%)$ presented compensatory sweating on the back, a significantly higher proportion than that observed for the patients a BMl $\leq 24.9 \mathrm{~kg} / \mathrm{m}^{2}$ $(p=0.018)$. The proportion of patients reporting compensatory sweating on the back was also

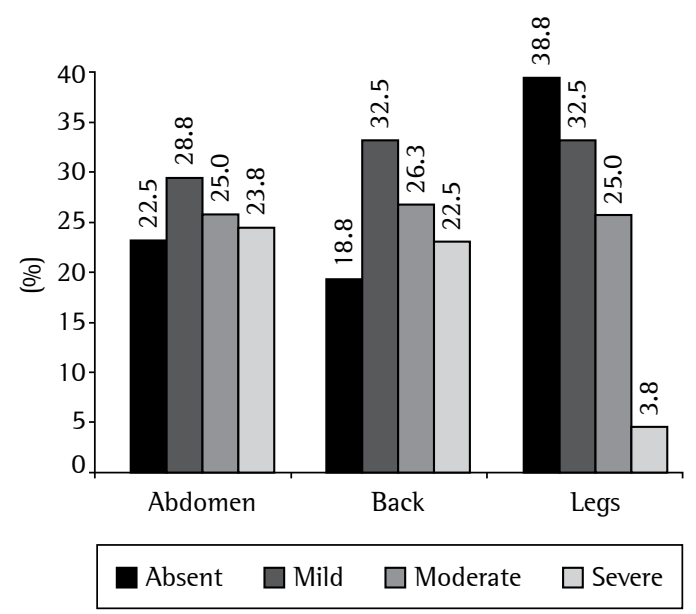

Figure $\mathbf{1}$ - Severity of compensatory sweating as a function of the affected area. 
greater among males than among females (45.8\% vs. $17.1 \% ; p=0.012)$.

\section{Discussion}

Although thoracoscopic sympathectomy is a well-established treatment for hyperhidrosis, it is empirical in nature, and compensatory sweating is a quite common adverse effect that plays a major role in determining the level of patient satisfaction. ${ }^{(5,7-10,12)}$ The reported incidence of post-operative compensatory sweating ranges from $30 \%$ to $84 \% .^{(12)}$ There have been discrepancies among studies in terms of the results and complication rates reported, due in part to the lack of clear-cut criteria for selecting surgical candidates, failed procedures, complications and side effects, as well as to differences in the collection of short- and long-term follow-up data. ${ }^{(5)}$ In the present study, $85 \%$ of the patients presented compensatory sweating. High rates of compensatory sweating are expected in countries with hot and humid climates, given that climate plays a major role in the occurrence of compensatory sweating, as demonstrated in two studies conducted in Taiwan, ${ }^{(13,14)}$ in which $98 \%$ of the patients evaluated complained of compensatory sweating. In a study conducted in Brazil, the reported rate of compensatory sweating was $63 \% .^{(5)}$

Although post-operative compensatory sweating is quite common, it rarely impairs patient quality of life, ${ }^{(5,8,9,12)}$ and the level of patient satisfaction with the surgical outcome is therefore quite high. In one study, it was reported that, although the rate of compensatory sweating was high (63\%), 79.7\% of the patients were completely satisfied with the outcome of the operation, having experienced immediate and permanent relief from the sweating or other symptoms. ${ }^{(5)}$ Our findings are in agreement with those of that report. Despite the fact that the compensatory sweating rate was 85\%, 87.5\% of the patients were satisfied with the outcome of the operation. The high degree of patient satisfaction might be attributable to the fact that the compensatory sweating caused neither social nor professional embarrassment. In fact, the compensatory sweating was severe in only $22(32.4 \%)$ of the 68 patients affected.

Many factors might play a role in the occurrence of compensatory sweating. In a study involving 134 patients, ${ }^{(15)}$ the influence that age, gender, family history and combined plantar hyperhidrosis have on the occurrence and severity of post-operative compensatory sweating was studied using multivariate analysis. The authors found that age was the sole variable associated with a statistically significant increase in the occurrence of compensatory sweating but not with that of severe compensatory sweating. This is in agreement with the age-related differences observed in our study sample, in which the satisfied group consisted mainly of adults and adolescents (72.8 and 22.8\%, respectively). However, our findings differed in other aspects, such as the influence of gender, the level of satisfaction being significantly higher among the females evaluated in our study $(p=0.026)$.

Nutritional state is another important point to consider. One group of authors showed that higher BMl predisposes to more severe post-operative compensatory sweating, although this is not necessarily reflected in patient level of satisfaction. ${ }^{(8)}$ The authors suggested that patients with high BMl presented profuse sweating on the abdomen and back prior to surgery, and that the level of patient satisfaction was influenced not only by the result but also by expectations with regard to complications. They considered greater patient awareness of all possible side effects to play an important role in determining the level of satisfaction. This was not entirely the case for our results, in which BMl also affected the level of satisfaction. Although all of our patients were duly informed regarding the possible side effects, those with a BMl $>24.9 \mathrm{~kg} / \mathrm{m}^{2}$ were more likely to report dissatisfaction. In fact, the influence of $\mathrm{BMl}$ on the severity of compensatory sweating and on the level of patient satisfaction has not been widely investigated.

The extent of denervation has frequently been addressed in recent years. ${ }^{(3,9,13,16,17)}$ One study showed that patients submitted to oneport sympathectomy present better outcomes in terms of length of hospital stay, rate of postoperative pneumothorax, and the need for chest tube placement, although the number of ports was not found to correlate with the level of patient satisfaction. ${ }^{(16)}$ Another study analyzed the effectiveness of and complications following one- and two-ganglion resection in patients with palmar hyperhidrosis. The effectiveness of the one-ganglion resection was less than optimal due to a high rate of post-operative 
compensatory sweating. It was concluded that two-ganglion (T2 and T3) resection is preferable because it improved satisfaction rates. In fact, the rate of compensatory sweating was lower among the patients submitted to twoganglion resection, even if it may subsequently cause compensatory sweating of slightly greater severity. ${ }^{(13)}$ This remains the subject of debate. In another study, 24 patients underwent T2-T3 sympathectomy and 30 patients underwent selective T3 sympathectomy. It was found that one-ganglion thoracoscopic sympathectomy resulted in a fewer disturbing side effects than did the two-ganglion version of the procedure. ${ }^{(17)}$

The severity of compensatory sweating might be reduced by limiting the extent of the denervation. When denervation is restricted, compensatory sweating is expected to be mild. ${ }^{(12)}$ Selective T3 sympathectomy resulted in a lower rate of compensatory sweating rate (17\%), compared with conventional T2 and T3 sympathectomy (46\%).. ${ }^{(17)}$ These results are consistent with our findings, since our patients who underwent more limited denervation, especially when the sympathectomy was performed at the lower levels, were more likely to have a favorable outcome.

The body area affected by compensatory sweating is another important point. In a recent study it was reported that the areas most often affected by compensatory sweating were the chest, back, legs, abdomen, thighs and groin.(1) In fact, the most common locations for compensatory sweating described in the literature, and corroborated in our study, are the abdomen, back, feet and buttocks. ${ }^{(18,19)}$ The present study also addressed the relationship between the severity of compensatory sweating and the affected area, as well as the roles played by age, gender and BMl. It was found that compensatory sweating on the chest was generally mild for adolescents and young adults, whereas it was generally severe for middle-aged patients. On the chest and on the back, compensatory sweating was generally mild or moderate in women. Patients with a $\mathrm{BMl} \leq 24.9 \mathrm{~kg} / \mathrm{m}^{2}$ presented mild compensatory sweating on the back. It would be quite interesting to compare our findings with those of other studies. However, there is a paucity of data on this topic in the literature.
Sympathectomy is a safe and effective method of treating hyperhidrosis. However, the incidence of post-operative compensatory sweating is high. In most cases, it is tolerable and does not represent a social or occupational handicap. Patients are inconvenienced only when their symptoms are severe or when they do not receive adequate information prior to the procedure. Patients must always be advised of this potential complication before they decide to undergo surgery. In the present study, a number of factors were found to be related to the occurrence and severity of compensatory sweating. Based on our findings, we can conclude that the ideal candidate is a young adult female with a BMl $<25 \mathrm{~kg} / \mathrm{m}^{2}$. To prevent compensatory sweating, appropriate patient selection is required. In addition, limited denervation, especially when the sympathectomy is performed at the lower levels, is advisable. Our results are encouraging and should stimulate further comparative studies to investigate this important issue.

\section{References}

1. Dewey TM, Herbert MA, Hill SL, Prince SL, Mack MJ. One-year follow-up after thoracoscopic sympathectomy for hyperhidrosis: Outcomes and consequences. Ann Thorac Surg. 81(4):1227-32; discussion 1232-3.

2. Baumgartner FJ, Toh Y. Severe hyperhidrosis: Clinical features and current thoracoscopic surgical management. Ann Thorac Surg. 2003;76(6):1878-83.

3. Schmidt J, Bechara FG, Altmeyer P, Zirngibl H. Endoscopic thoracic sympathectomy for severe hyperhidrosis: Impact of restrictive denervation on compensatory sweating. Ann Thorac Surg. 2006;81(3):1048-55.

4. Dumont P, Denoyer A, Robin P. Long-term results of thoracoscopic sympathectomy for hyperhidrosis. Ann Thorac Surg. 2004;78(5):1801-7.

5. de Campos JR, Kauffman P, Werebe ED, Andrade LO, Kusniek S, Wolosker N, et al. Quality of life, before and after thoracic sympathectomy: report on 378 operated patients. Ann Thorac Surg. 2003;76(3):886-91.

6. de Campos JR, Kauffman P, Werebe ED, AndradeFilho LO, Kusniek S, Wolosker N, et al. Questionário de qualidade de vida em pacientes com hiperidrose primária. J Pneumol. 2003;29(4):178-81.

7. Lima AG, Marcondes GA, Teixeira AB, Toro IF, Campos JR, Jatene FB. The incidence of residual pneumothorax after video-assisted sympathectomy with and without pleural drainage and its effect on postoperative pain. $\mathrm{J}$ Bras Pneumol. 2008;34(3):136-42.

8. Licht PB, Pilegaard HK. Severity of compensatory sweating after thoracoscopic sympathectomy. Ann Thorac Surg. 2004;78(2):427-31.

9. Baumgartner F. Compensatory hyperhidrosis after thoracoscopic sympathectomy. Ann Thorac Surg. 2005;80(3):1161; author reply 1161 .

10. Montessi J, Almeida EP, Vieira JP, Abreu Mda M, Souza RL, Montessi OV. Video-assisted thoracic sympathectomy 
in the treatment of primary hyperhidrosis: a retrospective study of 521 cases comparing different levels of ablation. J Bras Pneumol. 2007;33(3):248-54.

11. Andrews BT, Rennie JA. Predicting changes in the distribution of sweating following thoracoscopic sympathectomy. Br J Surg. 1997;84(12):1702-4.

12. de Campos JR, Wolosker N, Takeda FR, Kauffman P, Kuzniec S, Jatene FB, et al. The body mass index and level of resection: predictive factors for compensatory sweating after sympathectomy. Clin Auton Res. 2005;15(2):116-20.

13. Lin TS, Fang HY. Transthoracic endoscopic sympathectomy in the treatment of palmar hyperhidrosis-with emphasis on perioperative management $(1,360$ case analyses). Surg Neurol. 1999;52(5):453-7.

14. Yano M, Kiriyama M, Fukai I, Sasaki H, Kobayashi $Y$, Mizuno K, et al. Endoscopic thoracic sympathectomy for palmar hyperhidrosis: Efficacy of T2 and T3 ganglion resection. Surgery. 2005;138(1):40-5.

15. Lai YT, Yang LH, Chio CC, Chen HH. Complications in patients with palmar hyperhidrosis treated with transthoracic endoscopic sympathectomy. Neurosurgery. 1997;41(1):110-3; discussion 113-5.

16. Lesèche G, Castier Y, Thabut G, Petit MD, Combes M, Cerceau 0, et al. Endoscopic transthoracic sympathectomy for upper limb hyperhidrosis: limited sympathectomy does not reduce postoperative compensatory sweating. J Vasc Surg. 2003;37(1):124-8.

17. Murphy MO, Ghosh J, Khwaja N, Murray D, Halka AT, Carter A, et al. Upper dorsal endoscopic thoracic sympathectomy: a comparison of one- and two-port ablation techniques. Eur $\mathrm{J}$ Cardiothorac Surg. 2006;30(2):223-7.

18. Yoon SH, Rim DC. The selective T3 sympathicotomy in patients with essential palmar hyperhidrosis. Acta Neurochir (Wien). 2003;145(6):467-71; discussion 471.

19. Munia MA, Wolosker N, Kauffman P, de Campos JR, Puech-Leão $\mathrm{P}$. A randomized trial of T3-T4 versus T4 sympathectomy for isolated axillary hyperhidrosis. J Vasc Surg. 2007;45(1):130-3.

\section{About the authors}

\section{Carlos Alberto Almeida de Araújo}

Adjunct Professor. Department of Integrated Medicine, Universidade Federal do Rio Grande do Norte - UFRN, Federal University of Rio Grande do Norte - Natal, Brazil.

\section{Ítalo Medeiros Azevedo}

Statistician. Department of Surgery, Universidade Federal do Rio Grande do Norte - UFRN, Federal University of Rio Grande do Norte - Natal, Brazil.

\section{Maria Angela Fernandes Ferreira}

Associate Professor. Odontology Department, Universidade Federal do Rio Grande do Norte - UFRN, Federal University of Rio Grande do Norte - Natal, Brazil.

\section{Hylas Paiva da Costa Ferreira}

Substitute Professor. Department of Internal Medicine, Universidade Federal do Rio Grande do Norte - UFRN, Federal University of Rio Grande do Norte - Natal, Brazil.

\section{Jorge Lúcio Costa de Medeiros Dantas}

Physician for the city of Natal, Natal, Brazil.

\section{Aldo Cunha Medeiros}

Full Professor. Postgraduate Program in Health Sciences, Universidade Federal do Rio Grande do Norte - UFRN, Federal University of Rio Grande do Norte - Natal, Brazil. 
Appendix 1 - Sweating scores.

\begin{tabular}{lll}
\hline Location & Score (0-10) & \\
\cline { 2 - 3 } & Before surgery & After surgery \\
Prmpits & & \\
Face & & \\
Feet & & \\
Abdomen & & \\
Back & & \\
Legs & & \\
\hline
\end{tabular}

Source: Andrews \& Rennie. ${ }^{(11)}$ 